\title{
Field evaluation of a recombinant glutathione S-transferase-based pyrethroid quantification assay
}

\author{
Ahmad Ali Enayati ${ }^{a, 1}$, Christian Lengeler $^{\mathrm{b}}$, Tobias Erlanger $^{\mathrm{b}}$, \\ Janet Hemingway ${ }^{a, *}$
}

a Liverpool School of Tropical Medicine, Pembroke Place, Liverpool L3 5QA, UK

b Swiss Tropical Institute, P.O. Box, 4002, Basel, Switzerland

Received 10 May 2004; received in revised form 2 September 2004; accepted 6 September 2004

KEYWORDS

Malaria;

Glutathione

S-transferase;

Insecticide

quantification;

Field assay;

Field validation;

Tanzania

\begin{abstract}
Summary A recombinant glutathione S-transferase (GST)-based pyrethroid quantification assay was field-tested in Ifakara, Tanzania. Initial laboratory tests suggested that all reagents used in the assay should be sufficiently stable for field use, provided that domestic refrigeration facilities were available. Insecticideimpregnated bednets were collected from a region where a social marketing programme was in progress. A total of 100 bednets were collected and the assay plus standard HPLC analysis was performed on the residues extracted from four replicate areas of each net. Insecticide residue estimations for assays performed on white and pale green bednet samples were accurate when compared with residue analysis by HPLC. However, for dark green or blue bednets, there was no correlation between the GST-based assay and HPLC pyrethroid quantification results. The assay failure with the dark coloured nets was caused by the extraction of the dyes along with the insecticide, which subsequently interfered with the GST assay. When the same samples were analysed by HPLC, the dyes were separated from the insecticide by reverse phase column chromatography and hence did not affect the results.

(c) 2004 Royal Society of Tropical Medicine and Hygiene. Published by Elsevier Ltd. All rights reserved.
\end{abstract}

\section{Introduction}

The international Roll Back Malaria partnership is currently promoting the use of insecticide-treated nets (ITN) as one of the major preventive tools in the global fight against malaria (RBM, 2003). The international public health community, and the African Heads of State who met in Abuja, Nigeria,

\footnotetext{
* Corresponding author. Tel.: +44 1517053261;

fax: +44 1517070155 .

E-mail address: hemingway@liverpool.ac.uk (J. Hemingway).

1 Present address: School of Public Health, Vesal Street, Amir Boulevard, Sari, Iran.
} 
in 2000, have committed themselves to protecting $60 \%$ of all pregnant women and small children with ITNs by 2005. In endemic areas, ITNs reduce the number of clinical malaria episodes by roughly $50 \%$ and improve infant survival by nearly a fifth (Lengeler, 2000).

There are, however, still a number of unresolved operational issues that inhibit maximization of the benefits afforded by ITNs. One of the main operational issues faced by ITN programmes is the lack of regular insecticide re-treatment of existing nets (Armstrong-Schellenberg et al., 2002; Chavasse et al., 1999; Snow et al., 1999). This is a problem for two reasons. Firstly, nets that are not treated with insecticide provide only about half the epidemiological impact that treated nets have (Lengeler, 2000). Hence, the failure to add the insecticide, by far the cheaper of the two ITN components (net and insecticide), means that a large impact is missed. Secondly, bednets with a sublethal insecticide concentration are still attractive to bloodseeking mosquitoes because of the carbon dioxide emissions from people sleeping under them (Lines et al., 1987), and might rapidly select for resistant vectors. Hence, improved insecticide treatment strategies need to be developed and promoted on a large scale.

In this context, adequate monitoring of net impregnation status should be an integral part of ITN programmes, so that problems can be identified and addressed. Organizations distributing nets and treatment kits also need a simple quality control test to determine whether the initial treatment of the nets was adequate and to advise on the frequency of bednet re-treatment in specific contexts (Verle, 1998). The development and commercialization of nets with a long-lasting insecticide treatment (Guillet et al., 2001) will not change the situation in the foreseeable future because many conventionally treated nets will remain in place, and the insecticide, even on these new nets, may still not last as long as the net itself.

The easiest way to assess net treatment rates is simply to ask net owners whether they have treated or re-treated their net(s), and if so, how frequently. However, this approach is fraught with problems. There is a danger that respondents may feel obliged to answer the question in the affirmative during an active ITN campaign (Muller, 1994). A recent field survey in Tanzania has demonstrated that only a third of nets that were claimed to be treated during the last 12 months by their owners had an operationally effective insecticide dose on them (Erlanger et al., 2004).

Several studies have been conducted using bioassays of mosquitoes and chromatographic methods to evaluate the effective duration of treated bednets (Alonso et al., 1993; Miller et al., 1991), to assess the effects of washing on the insecticide content of ITNs (Miller et al., 1991; Rozendaal, 1989; Snow et al., 1987) and their wash-fastness (Lindsay et al., 1991b). However, due to limitations in the methodologies used, the results of such studies have only given rough estimates of insecticide concentrations. Bioassays of susceptible mosquitoes on treated bednets can be used to obtain an indication of biological activity of ITNs, using a correlation between the mortality rates in test mosquitoes and exposure time (Beach et al., 1993; Hossain et al., 1989; Jawara et al., 1998; Jinjiang et al., 1988; Lindsay et al., 1991a, 1993; Maxwell et al., 1999). However, this method is not particularly sensitive and requires access to susceptible live mosquitoes, a requirement beyond most ITN programmes. A modified Beilstein method can detect pyrethroid residues on bednets (Muller, 1994; Verle, 1998), but the method is not quantitative and lacks specificity in detecting pyrethroid insecticides on coloured bednets (Drakeley et al., 1999). Chromatographic (especially HPLC) and immunological methods are available for the detection of insecticide residues (Alonso et al., 1993; Beach et al., 1993; Hossain and Curtis, 1989; Hossain et al., 1989; Lindsay et al., 1991b; Shan et al., 1999a, 1999b; Wengatz et al., 1998) but they are technically demanding and do not meet the requirements for an easy, inexpensive field test that could be performed by inexperienced staff in the framework of ITN programmes.

Against this background, a novel pyrethroid insecticide detection and quantification method was developed, based on pyrethroid inhibition rates of a recombinant Anopheles gambiae glutathione S-transferase (agGST1-6) enzyme (Enayati et al., 2001). This assay is simple, relatively inexpensive, quantitative, and it should be suitable for field use. Here we present the results from the first validation of the feasibility and sensitivity of this assay under field conditions. We further evaluated the stability of the components and the temperature sensitivity of the assay.

\section{Materials and methods}

This pyrethroid quantification assay allows estimation of pyrethroid concentration by eye in an iodimetric format or by direct measurement of absorbance changes at $340 \mathrm{~nm}$. To establish whether the iodimetric assay was viable under field conditions, reagent stability was monitored. 


\subsection{Testing the stability and reactivity of assay reagents in the laboratory}

The stability of different components of the assay including the reduced glutathione (GSH), chlorodinitrobenzene (CDNB), buffer, iodine, starch and the recombinant glutathione S-transferase (GST) enzyme were investigated under different conditions in the Liverpool School of Tropical Medicine laboratory. Chemicals were stored in a wide matrix of different temperatures $\left(-20\right.$ to $\left.26^{\circ} \mathrm{C}\right)$, concentrations (concentrated stock solution or working solution) and formulations (manufacturer supplied formulation, lyophilized and working solution). The activity of the reagents stored under different situations was compared to those of freshly prepared reagents. For example, to determine the stability of GSH, its solution was stored at different temperatures for different time periods and then assayed with fresh assay reagents and the results were compared with the control where all components of the assay were freshly prepared.

The effects of temperature on the enzymesubstrate interaction, inhibition rates and iodine behaviour and iodimetric assays were assessed. The range of temperatures tested mimicked those under which the assay might be employed in the tropics. To this end, the microtitre plate reader chamber was maintained at different temperatures to measure residual recombinant GST activity in the presence of the insecticide. For the iodimetric assay, a thermostatically controlled water bath was kept at the same temperatures as those tested with the microtitre plate reader chamber. The remaining GSH in positive controls and inhibition reaction wells were titrated iodimetrically in the water bath immediately after kinetic reading of residual GST activity in the microtitre plate reader. The recombinant enzyme was preserved in different forms and conditions, such as glycerol stock kept at $-20^{\circ} \mathrm{C}$ or $4^{\circ} \mathrm{C}$, a working diluted solution at $-20^{\circ} \mathrm{C}, 4^{\circ} \mathrm{C}$ and room temperature or as a lyophilized enzyme. The activities of reaction mixtures containing freshly prepared reagents were compared to those of mixtures containing the same set of fresh reagents with differently prepared enzyme.

Glutathione S-transferase was purified as described by Enayati et al. (2001). As a lyoprotectant, sucrose $(0.6 \mathrm{mg} / \mathrm{ml})$ was added to the final volume of concentrated freshly purified enzyme. The enzyme solution was aliquoted into $50 \mu \mathrm{l}$ batches and frozen at $-70^{\circ} \mathrm{C}$, overnight. To lyophilize the enzyme, a few holes were made in the microfuge storage tube lids to allow evaporation and the tubes were placed into a lyophilizer at $-20^{\circ} \mathrm{C}$ and 6 millibars of pressure applied for three hours.
Lyophilized samples were kept at room temperature and $4^{\circ} \mathrm{C}$ and their activities were compared to that of purified enzyme from the same batch stored as a glycerol stock at $-20^{\circ} \mathrm{C}$.

\subsection{Field study area}

The field trial of the assay was undertaken at the Ifakara Health Research and Development Centre (IHRDC) which is situated in Ifakara Town, the administrative centre of Kilombero District, Morogoro Region, Tanzania. Basic laboratory facilities including refrigerators and freezers and other standard laboratory equipment were available at IHRDC, but in general it was representative of the facilities that might be found in many organizations throughout Africa. The area is holoendemic for malaria with transmission rates as high as 300 infective bites per year and high Anopheles mosquito densities (Smith et al., 1993). There has been an ongoing social marketing programme, the Kilombero Net Programme (KINET), promoting ITNs and insecticide treatment kits since 1997 (Schellenberg et al., 1999).

\subsection{Field sample collections}

Eighty-three net samples identified through a central KINET database were obtained from the study area. Owners were visited and those willing to exchange their used net were given a new ITN. In addition, 17 samples of nets and treated materials were supplied by Intelligent Insect Control, (Montpellier, France), to provide a wide range of net types and colonies to test the assay sensitivity. The field-collected samples were transferred to the IHRDC where the insecticide extractions and recombinant enzyme assays were undertaken. A sample of the extract from each net was then transferred to the Liverpool School of Tropical Medicine for HPLC analysis.

\subsection{Residue extraction}

Based on the original target dose of deltamethrin on bednets and the known percentage of insecticide recovered from bednets using an acetone extraction (Enayati et al., 2001), four identical $4.2 \mathrm{~cm}^{2}$ pieces of material from different areas of each bednet (side and top) were taken that should contain the equivalent amount of insecticide that gives maximum GST inhibition. These were soaked in $5 \mathrm{ml}$ acetone in a glass vial. The tubes were shaken for two minutes and the pieces of bednet were washed with $2 \mathrm{ml}$ of excess acetone in the same vial. The remaining acetone was squeezed out of the material 
before it was discarded. The extract was dried at room temperature and the residues from the four samples were combined by washing each vial sequentially with $3 \mathrm{ml}$ of acetone. The solution was placed into two $1.5 \mathrm{ml}$ Eppendorf tubes and centrifuged for $30 \mathrm{~min}$ at $15000 \mathrm{rpm}$. The supernatant was then divided into four aliquots, three of which were placed into separate glass tubes. The last aliquot was placed in a clean Eppendorf tube. The extracts in glass tubes were used for the iodimetric assay, while the extract in the Eppendorf tube was dried, dissolved in $50 \mu$ l acetonitrile, centrifuged at $15000 \mathrm{rpm}$ for $10 \mathrm{~min}$ and used for HPLC analysis at the Liverpool School of Tropical Medicine. Appropriate control replicates were prepared by extracting materials from untreated bednets of the same colour and size.

\section{5. lodimetric assay}

Figure 1 presents the field method of this pyrethroid quantification assay. The insecticide residue aliquots were air-dried and re-dissolved in $25 \mu \mathrm{l}$ ethanol containing $0.35 \mathrm{mM}$ CDNB. The mixture was combined with $450 \mu \mathrm{l}$ of $2.5 \mathrm{mM} \mathrm{GSH}$ in a sodium phosphate buffer $\mathrm{pH}$ 6.5. The same concentrations and volumes of reagents were combined with extracts from ten untreated bednets and used as controls. Recombinant -6 enzyme $(0.2 \mu \mathrm{g})$ was added and tubes were incubated at room temperature for 7 minutes. Starch solution $(20 \mu \mathrm{l}$ of a $0.4 \%$ solution) was added to each tube and iodine titration was performed by adding $2.5 \mathrm{mN}$ iodine solution drop-wise to each tube to reach an endpoint using a $1 \mathrm{ml}$ variable volume Gilson

(3)

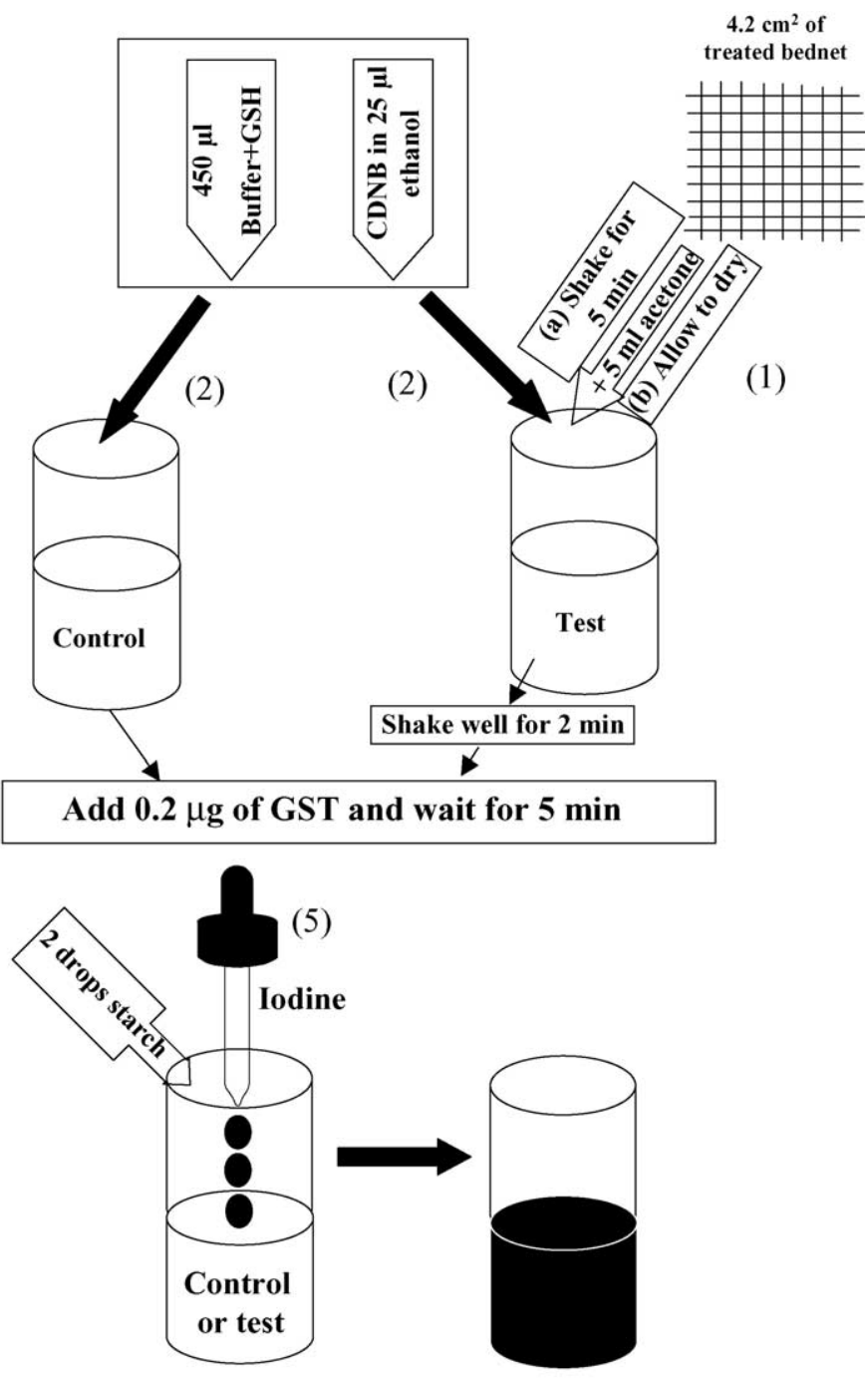

(6)

Record the volume of iodine needed for colour to change

Figure 1 Schematic diagram of the field kit designed to quantify the pyrethroid residue from treated bednets. 
micropipette. Alternatively, a syringe with a fine needle can be used as a dropper. It was essential during this procedure that the reaction mixture was not agitated too much as each iodine drop was added. The difference between the volume of iodine solution required to produce a blue colour in the test and control tubes was determined, and the actual concentration of insecticide on the bednet was calculated using the standard curve of iodimetric assays performed on bednets with known concentrations of insecticides.

\subsection{HPLC analysis of pyrethroid insecticides from bednets}

HPLC analysis was performed using a System Gold with a $166 \mathrm{UV} / \mathrm{Visible}$ detector and a 126 solvent module pump, equipped with an ODS ultrasphere reverse phase C18 column (Beckman, High Wycombe, Bucks, UK). The column was equilibrated with methanol:acetonitrile:distilled water (72.5:12.5:15) at ambient temperature with a flow rate of $0.7 \mathrm{ml} / \mathrm{min}$ and the peaks were detected at $210 \mathrm{~nm}$ by the UV detector. The extracted samples were re-dissolved in $50 \mu \mathrm{l}$ acetonitrile and were injected into the system manually. Insecticides were identified based on the shape and retention time of the peaks on the chromatogram and quantified against standard curves of authentic analytical grade insecticide.

\section{Results}

\subsection{Testing the reactivity of assay reagents in the laboratory}

A range of temperatures from 20 to $42^{\circ} \mathrm{C}$ were applied to the control and inhibited reaction mixtures for both spectrophotometric and iodimetric assays. Increasing the incubation temperature from 20 to $42{ }^{\circ} \mathrm{C}$ did not change the enzyme activity measured spectrophotometrically (Figure 2). The correlation of agGST1-6 inhibition rates and the volume of $5 \mathrm{mN}$ iodine solution consumed at different temperatures are depicted in Figure 3. No significant differences were observed in the rates of enzyme inhibition or in the volume of iodine solution needed in titration of mixtures at different temperatures $(P<0.001)$. Comparison between the slopes of the spectrophotometric and iodimetric assay regression lines, using a general linear model analysis in a Minitab programme, showed that the slopes of these lines were not significantly different from zero $(P=0.258)$. This means that pyrethroid quantification by spectrophotometric and iodimetric assays is identical over the temperature range tested.

\subsection{Stability of different components of the pyrethroid residue analysis kit under different conditions}

Different assay reagents were prepared and kept under a range of conditions before being used to

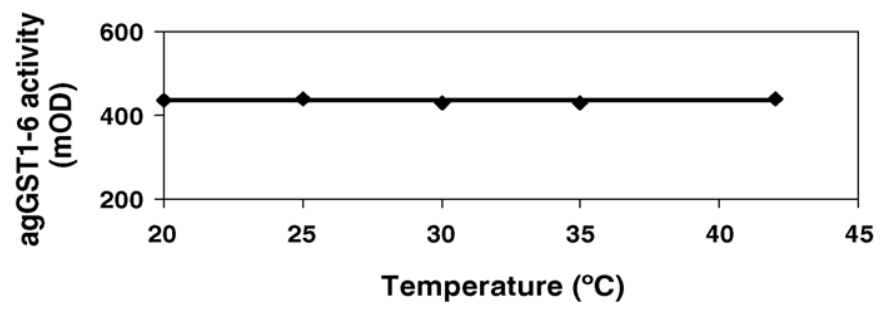

Figure 2 Effects of temperature on Anopheles gambiae glutathione-S transferase (agGST1-6) activity. Reaction mixtures contained: glutathione $=2.5 \mathrm{mM}$, chloro-dinitrobenzene $=0.35 \mathrm{mM}$, glutathione- $\mathrm{S}$ transferase $=0.1 \mu \mathrm{g}$, deltamethrin $=0.1 \mathrm{mM}$, iodine $=5 \mathrm{mN}$.

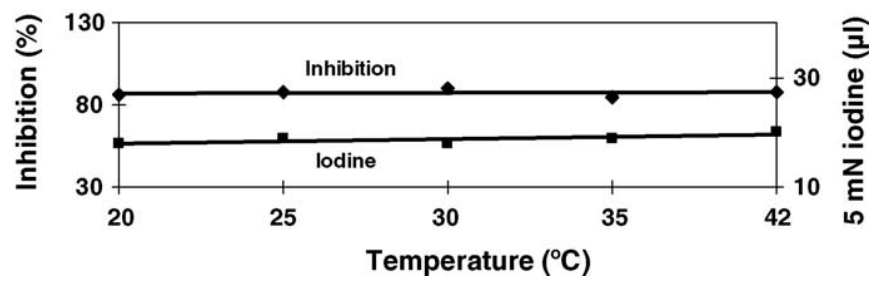

Figure 3 Effects of temperature on the inhibition rates of Anopheles gambiae glutathione-S transferase by deltamethrin and results of iodimetric assays (performed as in Figure 1). 
test the enzyme activity. Room temperature for these assays was $26^{\circ} \mathrm{C}$. Chloro-dinitrobenzene and GSH, which were purchased in crystal and powder forms respectively from Sigma (Poole, Dorset, UK), can be kept at $4^{\circ} \mathrm{C}$ until the manufacturer's expiry dates. As a working solution, however, CDNB retained its activity for about two weeks, whereas GSH lost much of its activity after five hours. Starch, supplied as a powder, was stable at room temperature for more than six months. Concentrated iodine solution was stable at room temperature in a lightproof glass bottle. The working solution of iodine was stable for five to six hours and hence must be made up fresh from the concentrate. The starch working solution $(0.4 \%)$ was stable at room temperature for 48-72 hours and for a week at $4{ }^{\circ} \mathrm{C}$, after which time fungal contamination occurred. Recombinant enzyme, preserved as a glycerol stock at $-20^{\circ} \mathrm{C}$, was stable for over a year, retaining more than $95 \%$ of its original activity. However, the glycerol stock of enzyme kept at $4{ }^{\circ} \mathrm{C}$ lost $50 \%$ of its activity in one week. The enzyme has a very short half-life at room temperature suggesting that glycerol stocks, if used in a kit, would need to be shipped on ice. In contrast, lyophilized enzyme was relatively stable at $4^{\circ} \mathrm{C}$ and room temperature. Table 1 summarizes the enzyme activity at different intervals after lyophilization. There were significant differences between the stability of the lyophilized enzyme activity of samples kept at room temperature compared to those kept at $4{ }^{\circ} \mathrm{C}(P<0.001)$ with the slopes of the regression lines of reduction in enzyme activi-

Table 1 Activities (in mOD) of lyophilized Anopheles gambiae glutathione-S transferase enzyme kept at room temperature or at $4^{\circ} \mathrm{C}$ for different time intervals after lyophilization

\begin{tabular}{|c|c|c|c|c|}
\hline \multirow[t]{2}{*}{ Day } & \multicolumn{2}{|c|}{$\begin{array}{l}\text { Enzyme activity } \\
(\mathrm{mOD})^{\mathrm{a}}\end{array}$} & \multicolumn{2}{|l|}{$\begin{array}{l}\text { Reduction in } \\
\text { activity (\%) }\end{array}$} \\
\hline & $\begin{array}{l}\text { Room } \\
\text { temperature }\end{array}$ & $4^{\circ} \mathrm{C}$ & $\begin{array}{l}\text { Room } \\
\text { temperature }\end{array}$ & $4^{\circ} \mathrm{C}$ \\
\hline $0 \mathrm{BL}$ & & $1000 \pm 23$ & & 0 \\
\hline $0 \mathrm{AL}$ & $1000 \pm 27$ & $1000 \pm 20$ & 0 & 0 \\
\hline 1 & $850 \pm 18$ & $860 \pm 16$ & 15 & 14 \\
\hline 4 & $830 \pm 16$ & $830 \pm 12$ & 17 & 17 \\
\hline 6 & $670 \pm 20$ & $810 \pm 18$ & 33 & 19 \\
\hline 11 & $630 \pm 12$ & $803 \pm 15$ & 37 & 19.7 \\
\hline 34 & $475 \pm 15$ & $755 \pm 14$ & 52.5 & 24.5 \\
\hline 50 & $291 \pm 11$ & $602 \pm 10$ & 70.9 & 39.8 \\
\hline 68 & $151 \pm 9$ & $350 \pm 8$ & 84.9 & 65 \\
\hline
\end{tabular}

BL: before lyophilization; AL: after lyophilization. Reaction mixtures contained: glutathione $=7 \mathrm{mM}$, chlorodinitrobenzene $=1 \mathrm{mM}$, enzyme $=0.2 \mu \mathrm{g}$.

a Values are mean \pm SEM of three or more assays. ties of lyophilized samples kept at room temperature and $4^{\circ} \mathrm{C}$ being significantly different $(P<0.03)$. The $\mathrm{RT}_{50}$ (period of time needed for $50 \%$ reduction in original activity) for lyophilized samples kept at room temperature was 32 days compared to 54 days for samples kept at $4{ }^{\circ} \mathrm{C}$. A lyophilized enzyme should, therefore, be used if a field kit is produced. Lyophilized enzyme, transferred at room temperature to the field was used to perform iodimetric assays on analytical grade insecticide samples and on insecticide extracted from ITNs. The results of the iodimetric assays using lyophilized enzyme were the same as those with the glycerol stock enzyme, which was transferred to Tanzania on dry ice, suggesting that both shipment methods are possible.

\subsection{Sampling}

The 83 bednets collected from the field and 17 from Intelligent Insect Control were categorized into four groups based on their colour: white (30), pale green for which the extracted materials were yellow in colour (26), blue (16) and dark green (28). All subsequent tests were stratified according to these four groups.

\section{4. lodimetric and HPLC analysis of the samples}

In order to establish a standard curve, iodimetric assays were performed on insecticide residues extracted from ITNs with 2, 6.25, 10 and $25 \mathrm{mg} / \mathrm{m}^{2}$ of deltamethrin. The results produced a standard curve with the equation $Y=3.29 X+10.67$ where $Y$ is the quantity in microlitres of $2.5 \mathrm{mN}$ iodine used in the iodimetric assays and $X$ is the estimated concentration of insecticide in $\mathrm{mg} / \mathrm{m}^{2}$. This equation was the basis of calculations to convert the amounts of consumed iodine to the actual concentration of insecticide.

lodimetric assays were performed on the residues extracted from 100 bednets and the results were validated by HPLC analysis of the pyrethroid

Table 2 Accuracy of the iodimetric assay on bednets of different colours

\begin{tabular}{llcc}
\hline Bednet colour & $\begin{array}{l}\text { No. nets } \\
\text { tested }\end{array}$ & $\begin{array}{l}\text { False }+ \text { ve } \\
\text { or }- \text { ve }\end{array}$ & $\begin{array}{l}\text { Failure rate } \\
\text { of assay }\end{array}$ \\
\hline White & 30 & 2 & 6.6 \\
Pale green & 26 & 4 & 15 \\
Dark green & 28 & 16 & 57 \\
Dark blue & 16 & 8 & 50 \\
\hline
\end{tabular}




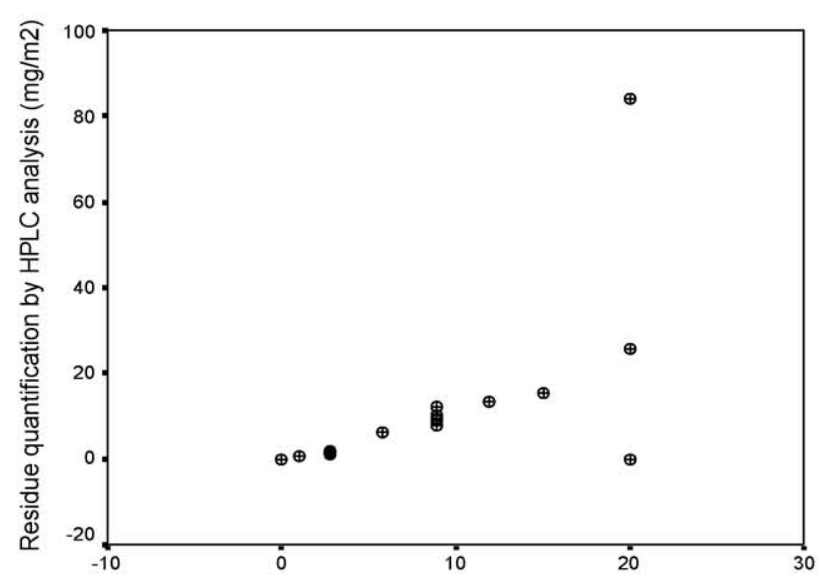

(a) Residue quantification by iodimetric assay $(\mathrm{mg} / \mathrm{m} 2)$

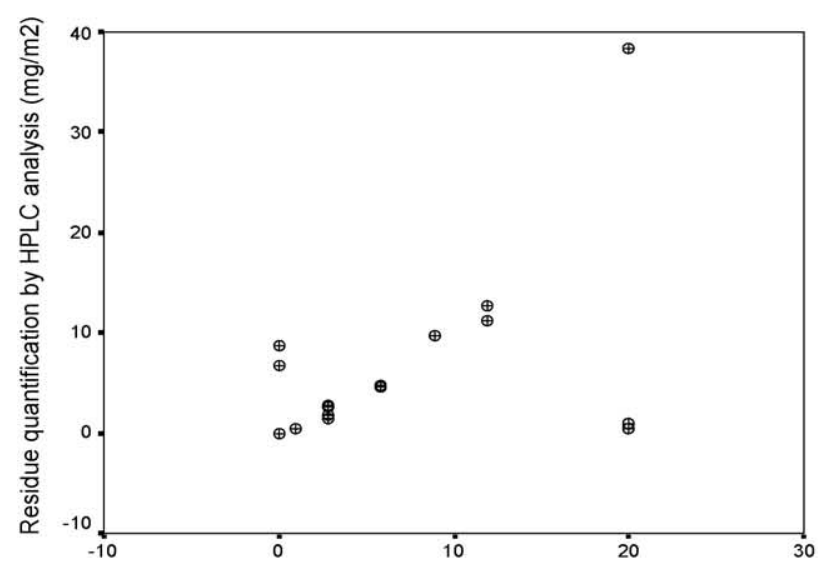

(c) Residue quantification by iodimetric assay $(\mathrm{mg} / \mathrm{m} 2)$

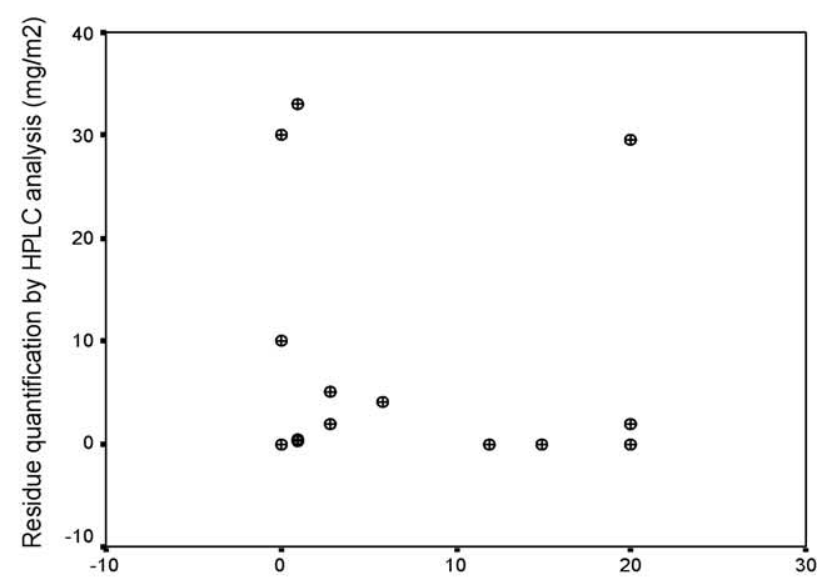

(b) Residue quantification by iodimetric assay $(\mathrm{mg} / \mathrm{m} 2)$

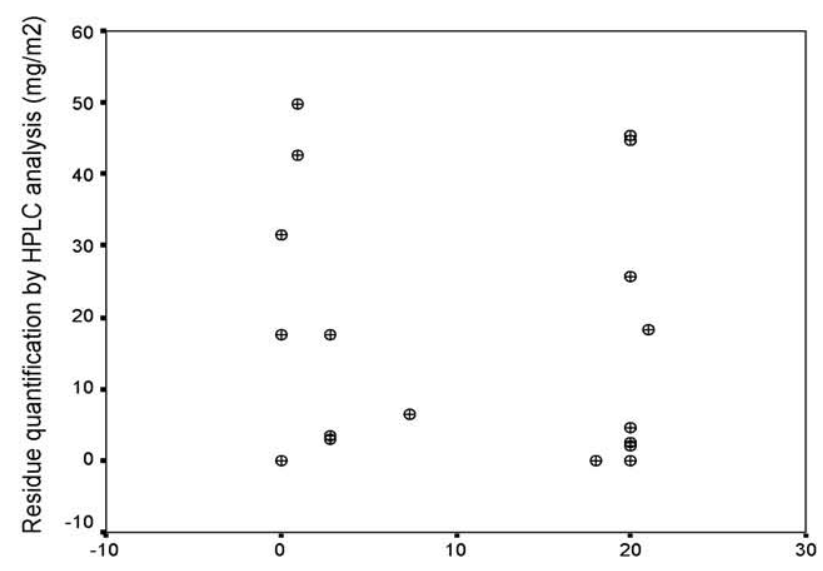

(d) Residue quantification by iodimetric assay $(\mathrm{mg} / \mathrm{m} 2)$

Figure 4 Scatter plots presenting the correlation between the results of iodimetric assays and HPLC analysis of residues extracted from bednets of different colours: (a) white bednets, (b) blue bednets, (c) pale green bednets and (d) green bednets.

residues extracted from the same bednets. The results are summarized in Table 2 . The iodimetric assays on white and pale green failed in only 6.6 and $15 \%$ of cases respectively. However, the failure rate with dark coloured bednets was more than $50 \%$. The correlation between the iodimetric assay and HPLC analysis of the residues extracted from different coloured bednets are presented as scatter plots in Figure 4. Pearson correlation tests showed that there was a significant correlation between the results of pyrethroid analysis for white and light coloured bednets by the two methods ( $r=0.81, P<0.001 ; r=0.77, P<0.001$ respectively). Hence the iodimetric assay performed satisfactorily with white and light coloured bednets under field conditions. There was, however, no significant correlation between the results of residue analysis obtained by the two methods for dark blue and dark green bednets $(r=0.04, P=0.875 ; r=0.219$,
$P=0.526$ respectively). Sensitivity and specificity were $96 \%$ and $80 \%$ respectively for white bednets and $88 \%$ and $78 \%$ respectively for pale green bednets. However the values for dark blue bednets for sensitivity and specificity were $57 \%$ and $44 \%$ respectively and $62 \%$ and $16 \%$ for dark green samples.

After testing, each net was classified according to its insecticide content. HPLC was used as the gold standard, against which the iodimetric assay was assessed. Bednets with an insecticide concentration of more than half the original treatment dose were considered as biologically active and those with insecticide concentrations of $<50 \%$ were categorized as negative nets. A cut-off value of $47 \mu \mathrm{l}$ or more of $2.5 \mathrm{mM}$ iodine solution consumed will, therefore, differentiate between deltamethrin positive and negative bednets. Hence, the residue from any bednet that requires 


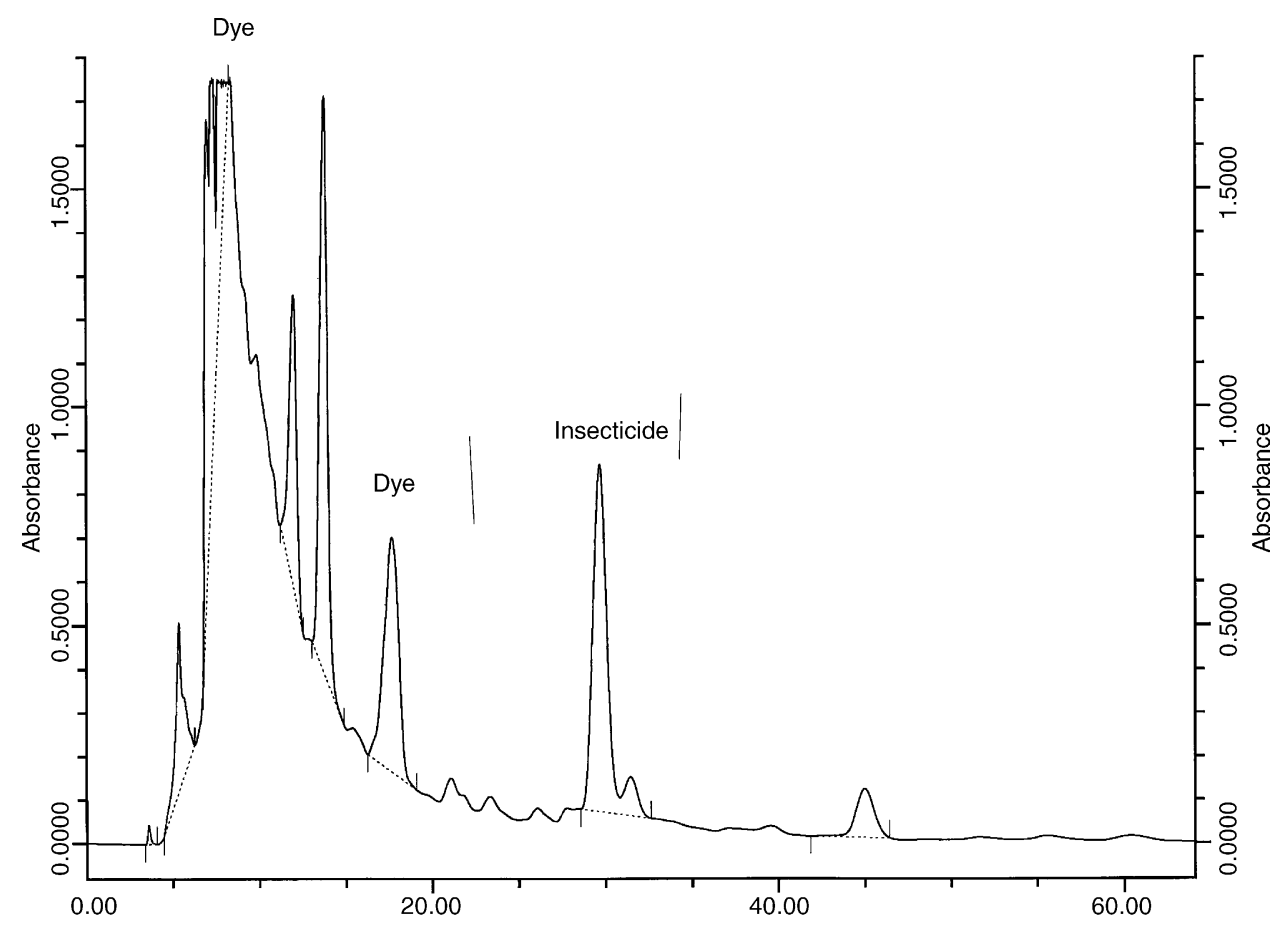

Figure 5 HPLC chromatogram for extract from a coloured bednet. The dye extracted along with insecticide from the bednet was separated from the insecticide by the mobile HPLC phase. The X-axis shows the retention time and the Y-axis shows the absorption at $210 \mathrm{~nm}$.

$47 \mu \mathrm{l}$ or more of $2.5 \mathrm{mM}$ iodine solution to turn the solution blue compared to the residue from a control net is considered to be biologically positive, i.e. it has $10 \mathrm{mg} / \mathrm{m}^{2}$ deltamethrin or more on the net. For the iodimetric and HPLC analytical assays and in calculation of the sensitivity and specificity of the iodimetric assay, the threshold of chemically positive and negative nets can be set as low as

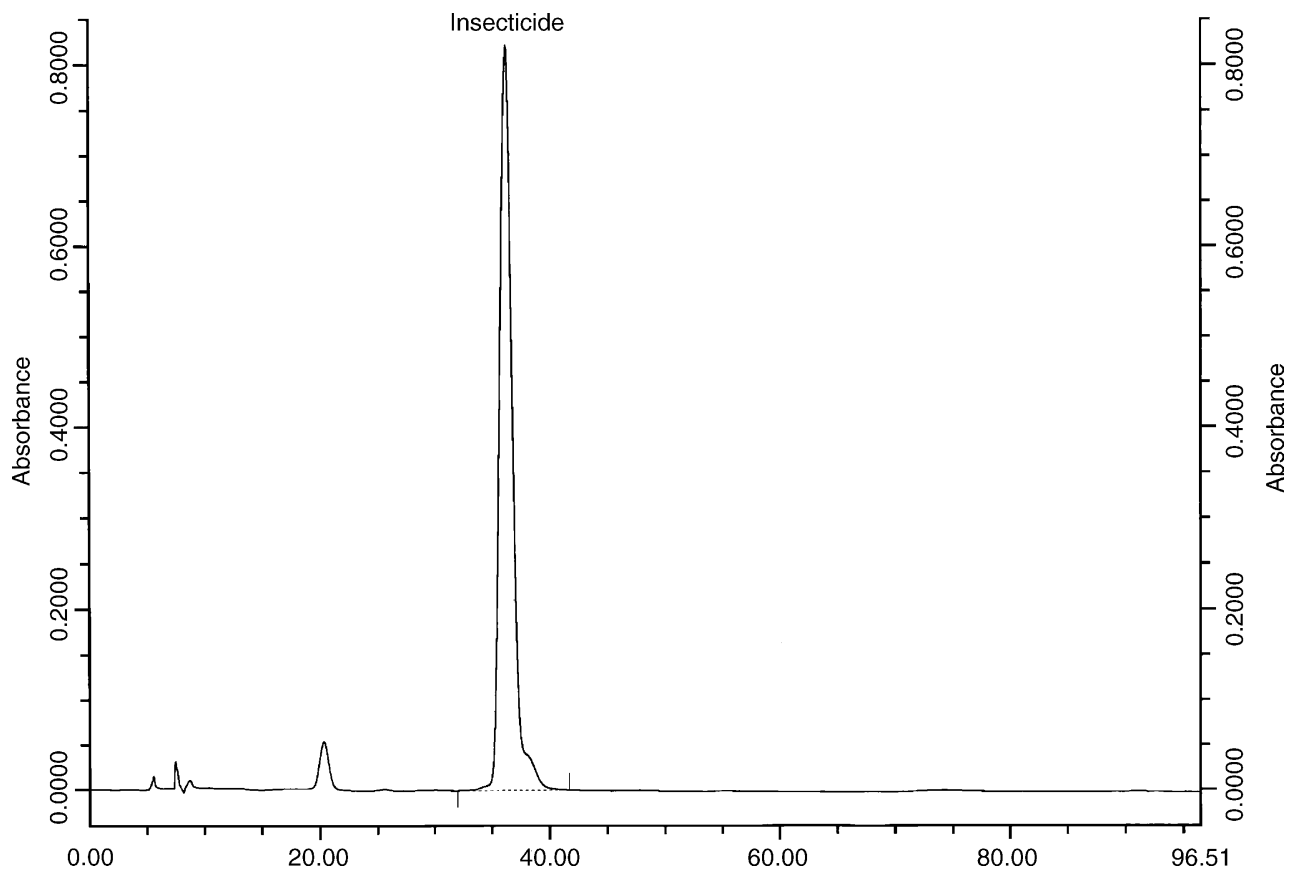

Figure 6 HPLC chromatogram of a light coloured bednet which only contains the extracted insecticide and no large dye peak. The $\mathrm{X}$-axis shows the retention time and the $\mathrm{Y}$-axis shows the absorption at $210 \mathrm{~nm}$. 
$2 \mathrm{mg} / \mathrm{m}^{2}$. HPLC chromatograms of dark coloured bednets had very big dye peaks, which had lower retention times than the insecticides (Figure 5). These peaks were absent in extracts from light coloured bednets (Figure 6). Under field conditions, the iodimetric titration part of the assay, and especially the judgement of the endpoint of the titration were the most sensitive issues. Consistency was essential in handling the different components of the assay, as any change in the rate at which the titration was performed in terms of shaking the titration mixture or speed of adding the iodine solution to the mixture led to different results.

\section{Discussion}

A recombinant GST-based pyrethroid residue analysis assay worked well under laboratory conditions with both analytical grade and formulated pyrethroids extracted from ITNs (Enayati et al., 2001). Before undertaking a field trial of the assay, the spectrophotometric and iodimetric pyrethroid quantification assays were performed at different temperatures in the laboratory to mimic tropical conditions. The enzyme activity and inhibition rates were not affected over a large range of ambient temperatures. This lack of temperature sensitivity is probably because the optimal temperature for the enzyme was not a major limiting factor at the reagent concentrations used in the reaction mixture. Therefore, the standard curves developed in the UK laboratory can be used to quantify the insecticide contents of unknown samples when the test is carried out in the field at temperatures up to $40^{\circ} \mathrm{C}$. The stability of the components of the pyrethroid residue analysis assay were examined under different storage conditions. The recombinant GST enzyme, potentially the most labile component of the assay, was stable as a glycerol stock at $-20^{\circ} \mathrm{C}$ for over a year. However, refrigerated enzyme solutions were stable for only one week. Tests using the lyophilized enzyme showed no difference with those performed with the glycerol stock of the enzyme. Lyophilized enzyme can be stored at room temperature or at $4{ }^{\circ} \mathrm{C}$ with a reduction in activity of $<50 \%$ for one to two months so is better stored at $4{ }^{\circ} \mathrm{C}$. Hence, the enzyme could be provided in lyophilized form for field applications where no reliable refrigeration system is available. Different handling of the iodimetric titration assay may reduce reproducibility. However, if the assay is handled consistently the results are reproducible and reliable. Control replicates should be run with each assay to ensure that errors, due to inconsistency, are removed.
The ITNs tested were categorized into four colour groups, i.e. white, pale green, dark green and dark blue. lodimetric assays were performed on three aliquots extracted from a combined pool of extracts from four different sections of each bednet. This sampling method was undertaken as patchy distribution of insecticide on nets can occur. The results of the iodimetric assays and HPLC analysis on the same ITN extracts showed $85 \%$ of white or lightly coloured nets were accurately analysed with a sensitivity and specificity of more than $80 \%$. This is an improvement over the modified Beilstein pyrethroid detection test (Muller, 1994; Verle, 1998), which lacks specificity in detecting pyrethroid residues on any coloured bednet and is unable to quantify the insecticide residues (Drakeley et al., 1999). However, for the dark coloured ITNs the dye extracted obscured the endpoint of the iodimetric titration process and the number of incorrect estimates of insecticide concentration was more than $50 \%$. Hence the assay in its current format is unsuitable for dark nets. The dye colour from dark nets did not interfere with HPLC analysis, as it separated from the insecticide during reverse phase column chromatography.

In summary, the iodimetric assay was relatively easy to use in the field, the assay and its components were stable under malaria-endemic area field conditions. The minimum requirements for using the assay in the field are a refrigerator and training to ensure the assay is standardized. However, the issue of interference by mosquito net dyes needs to be resolved before the assay can be recommended for large-scale programme monitoring.

\section{Conflicts of interest statement}

The authors have no conflicts of interest concerning the work reported in this paper.

\section{Acknowledgements}

This study was funded in part by the WHO and the DfID malaria knowledge programme. A. Enayati was supported by a studentship from the Iranian government.

\section{References}

Alonso, P.L., Lindsay, S.W., Armstrong-Schellenberg, J.R., Konteh, M., Keita, K., Marshall, C., Phillips, A., Cham, K., Greenwood, B.M., 1993. A malaria control trial using insecticidetreated bed nets and targeted chemoprophylaxis in a rural area of The Gambia, West Africa. 5. Design and implemen- 
tation of the trial. Trans. R. Soc. Trop. Med. Hyg. 87 (Suppl. 2), $S 2 / 31-S 2 / 36$.

Armstrong-Schellenberg, J., Minja, H., Mponda, H., Kikumbih, N., Mushi, A., Nathan, R., Abdulla, S., Mukasa, O.T.M., Tanner, M., Lengeler, C., 2002. Re-treatment of mosquito nets with insecticide. Trans. R. Soc. Trop. Med. Hyg. 96, 368-369.

Beach, R.F., Ruebush, T.K., Sexton, J.D., Bright, P.L., Hightower, A.W., Breman, J.G., Mount, D.L., Oloo, A.J., 1993. Effectiveness of permethrin impregnated bed nets and curtains for malaria control in a holoendemic area of Western Kenya. Am. J. Trop. Med. Hyg. 49, 290-300.

Chavasse, D., Reed, C., Attawell, K., 1999. Insecticide Treated Net Projects: a Handbook for Managers. Malaria Consortium, London and Liverpool.

Drakeley, C.J., Armstrong-Schellenberg, J., Abdulla, S., Lengeler, C., 1999. Short report: lack of specificity of Beilstein test in detecting pyrethroid insecticide on coloured mosquito nets. Trop. Med. Int. Health 4, 639-640.

Enayati, A.A., Vontas, J.G., Small, G.J., McCarroll, L., Hemingway, J., 2001. Quantification of pyrethroid insecticides from treated bednets using a mosquito recombinant glutathione S-transferase. Med. Vet. Entomol. 15, 58-63.

Erlanger, T.E., Enayati, A.A., Hemingway, J., Mshinda, H., Lengeler, C., 2004. Field issues related to effectiveness of insecticide-treated nets in Tanzania. Med. Vet. Ent. 18, $153-160$

Guillet, P., Alnwick, D., Cham, M.K., Neira, M., Zaim, M., Heymann, D., Mukelabai, K., 2001. Long-lasting treated mosquito nets: a breakthrough in malaria prevention. Bull. World Health Organ. 79, 998.

Hossain, M.I., Curtis, C.F., 1989. Permethrin-impregnated bednets: behavioural and killing effects on mosquitoes. Med. Vet. Entomol. 3, 367-376.

Hossain, M.I., Curtis, C.F., Heekin, J.P., 1989. Assays of permethrin impregnated fabrics and bioassays with mosquitoes. Bull. Ent. Res. 79, 299-308.

Jawara, M., McBeath, J., Lines, J.D., Pinder, M., Sanyang, F., Greenwood, B.M., 1998. Comparison of bednets treated with alphacypermethrin, permethrin or lambdacyhalothrin against Anopheles gambiae in the Gambia. Med. Vet. Entomol. 12, 60-66.

Jinjiang, X., Meiluan, Z., Xinfu, L., Rongen, G., Shixian, P., Shuyou, L., 1988. Evaluation of permethrin-impregnated mosquito-nets against mosquitoes in China. Med. Vet. Ent. 2, 247-251.

Lengeler, C., 2000. Insecticide-treated bednets and curtains for preventing malaria. Cochrane Database Syst Rev, CD000363.

Lindsay, S.W., Adiamah, J.H., Miller, J.E., Armstrong, J.R., 1991a. Pyrethroid-treated bednet effects on mosquitoes of the Anopheles gambiae complex in The Gambia. Med. Vet. Entomol. 5, 477-483.

Lindsay, S.W., Hossain, M.I., Bennett, S., Curtis, C.F., 1991b. Preliminary studies on the insecticidal activity and wash-fastness of 12 pyrethroid treatments impregnated into bednetting assayed against mosquitos. Pestic. Sci. 32, 397-411.

Lindsay, S.W., Alonso, P.L., Armstrong-Schellenberg, J.R., Hemingway, J., Adiamah, J.H., Shenton, F.C., Jawara, M., Greenwood, B.M., 1993. A malaria control trial using insecticidetreated bed nets and targeted chemoprophylaxis in a rural area of The Gambia, West Africa. 7. Impact of permethrinimpregnated bed nets on malaria vectors. Trans. R. Soc. Trop. Med. Hyg. 87 (Suppl. 2), S2/45-S2/51.

Lines, J.D., Myamba, J., Curtis, C.F., 1987. Experimental hut trials of permethrin-impregnated mosquito nets and eave curtains against malaria vectors in Tanzania. Med. Vet. Entomol. 1, 37-51.

Maxwell, C.A., Myamba, J., Njunwa, K.J., Greenwood, B.M., Curtis, C.F., 1999. Comparison of bednets impregnated with different pyrethroids for their impact on mosquitoes and on re-infection with malaria after clearance of pre-existing infections with chlorproguanil-dapsone. Trans. R. Soc. Trop. Med. Hyg. 93, 4-11.

Miller, J.E., Lindsay, S.W., Armstrong, J.R., 1991. Experimental hut trials of bednets impregnated with synthetic pyrethroid or organophosphate insecticide for mosquito control in The Gambia. Med. Vet. Entomol. 5, 465-476.

Muller, O., 1994. Detecting permethrin on treated bednets. Lancet 344, 1699-1700.

RBM, 2003. Scaling up Sustainable Impact. Strategic Orientations 2004-2008. Roll Back Malaria Partnership, World Health Organization, Geneva.

Rozendaal, J.A., 1989. Impregnated mosquito nets and curtains for self-protection and vector control. Trop. Dis. Bull. 86, r1-r41.

Schellenberg, J.R., Abdulla, S., Minja, H., Nathan, R., Mukasa, O., Marchant, T., Mponda, H., Kikumbih, N., Lyimo, E., Manchester, T., Tanner, M., Lengeler, C., 1999. KINET: a social marketing programme of treated nets and net treatment for malaria control in Tanzania, with evaluation of child health and long-term survival. Trans. R. Soc. Trop. Med. Hyg. 93, 225-231.

Shan, G., Stoutamire, D.W., Wengatz, I., Gee, S.J., Hammock, B.D., 1999a. Development of an immunoassay for the pyrethroid insecticide Esfenvalerate. J. Agric. Food Chem. 47, 2145-2155.

Shan, G., Wengatz, I., Stoutamire, D.W., Gee, S.J., Hammock, B.D., 1999b. An enzyme-linked immunosorbent assay for the detection of Esfenvalerate metabolites in human urine. Chem. Res. Toxicol. 12, 1033-1041.

Smith, T.A., Charlwood, J.D., Kihonda, J., Mwankusye, S., Billingsley, P., Meuwissen, J., Lyimo, E., Takken, W., Teuscher, T., Tanner, M., 1993. Absence of seasonal variation in malaria parasitaemia in an area of intense seasonal transmission. Acta Trop. 54, 55-72.

Snow, R.W., Jawara, M., Curtis, C.F., 1987. Observation on Anopheles gambiae Giles s.l. (Diptera: Culicidae) during a trial of permethrin-treated bed nets in The Gambia. Bull. Entomol. Res. 77, 279-286.

Snow, R.W., McCabe, E., Mbogo, C.N., Molyneux, C.S., Some, E.S., Mung'ala, V.O., Nevill, C.G., 1999. The effect of delivery mechanisms on the uptake of bed net re-impregnation in Kilifi District, Kenya. Health Policy Plan. 14, 18-25.

Verle, P., 1998. A simple field test for detecting pyrethroids on impregnated nets. Trop. Med. Int. Health 3, 833-836.

Wengatz, I., Stoutamire, D.W., Gee, S.J., Hammock, B.D., 1998. Development of an enzyme-linked immunosorbent assay for the detection of the pyrethroid insecticide fenpropathrin. J. Agric. Food Chem. 46, 2211-2221.

Available online at www.sciencedirect.com

science@direct 